\title{
Student Perceptions After Touching vs. Holding Educational Animals
}

\author{
L. Gilmer ${ }^{1}$, N. Fuhrman ${ }^{2}$
}

\begin{abstract}
Educators often use small animals as ambassadors of agricultural and environmental messages during presentations. These animals may include rabbits, chickens, and reptiles such as turtles and snakes. Although learners may be provided opportunities to touch or hold these animals, this presents a variety of safety and liability issues for the learner and animal. Little is known about whether touching or holding an animal influences perceptions of the animal and related agricultural and environmental issues. This qualitative study investigated the perceptions of 16 fifth grade students who experienced a live, tactile encounter with a corn snake and Eastern box turtle while participating in an educational class using four focus groups. Regardless of whether students touched the snake or turtle, or fully held the animal, participants noted the uniqueness of the experience and their empathy for the animal and its habitat. Students who fully held the animal thought that they learned more during the experience while students who touched the animal mentioned getting to know the animal better, regardless of whether the animal was a snake or turtle. When learners are unable to completely hold small animals, educators should consider the equally positive outcomes that can result from touching these animals.
\end{abstract}

\section{Keywords}

agricultural education, animal ambassadors, environmental education, experiential learning, reptiles as teaching tools

1. Lauryn Gilmer, County Extension Agent - 4-H, University of Georgia, P.O. Box 510 Jesup, GA 31598, lauryn.gilmer@uga.edu, ID https://orcid.org/0000-0002-6603-8760

2. Nick Fuhrman, Meigs Professor of Environmental Education, University of Georgia, Department of Agricultural Leadership, Education and Communication, 135 Four Towers Building, Athens, GA 30602, fuhrman@uga.edu, 


\section{Introduction and Problem Statement}

Many children in rural and urban areas alike have had little to no experience with native wildlife in their communities. The combination of increased urbanization, dwindling natural spaces, and increased time indoors has sparked concerns regarding children's diminishing direct contact with nature and agriculture (Louv, 2006; Strife \& Downey, 2009). Agricultural and environmental educators often use small animals such as rabbits, chickens, and reptiles as ambassadors of educational messages to build agricultural and environmental literacy during presentations to children because of their ease of transport and handling (Fuhrman \& Ladewig, 2008; Siegel, 2004). Exposure to live animals, including reptiles, in educational settings can reduce stress, provide hands-on learning experiences, and even enhance rapport between educators and learners (Fuhrman \& Rubenstein, 2017; Hummel \& Randler, 2012; Von Bergen, 2015).

Educators who provide safe animal encounters can create a more inclusive educational environment (Siegel, 2004) and promote lifelong learning opportunities (Newberry et al., 2017), one of the United Nations' Sustainable Development Goals (United Nations, n.d.). Engaging youth with animals they are more likely to see locally can also provide benefits. Some suggest that increasing knowledge in youth of the most common local organisms is crucial: in practice, most individuals have far greater opportunities to protect local biodiversity rather than to protect exotic species and learners are more likely to interact with native species on a daily basis (Ballouard et al., 2011; Kreger \& Mench, 1995). Conclusions from Trainin et al. (2005) posit that in the classroom with children, uniqueness of the animal visiting the students impacts their perceptions of it. Although agricultural and environmental educators alike are encouraged to provide safe animal encounters to emphasize human-animal connections (Pedersen, 2010), little is known about whether the intensity of a learner's touching or holding encounter with an animal influences perceptions of it and the overall environment in which they are learning.

Animals can help educators move learners along the continuum from awareness to action and they can help accelerate the agricultural, environmental, and even health literacy of students (Balis et al., 2019; Hudson, 2001). While educators may not have direct access to captive wildlife such as reptiles, agricultural animals, including goats, have been used to promote physical and mental health during "goat yoga" (Balis et al., 2019) while pet rabbits have helped reduce anxiety in youth in a classroom environment (Daly \& Suggs, 2010; Siegel, 2004). However, touching and holding educational animals presents a variety of safety and liability issues for the learner and animal alike. Knowledge of whether animal interaction intensity influences perceptions of the animal is needed to justify the risks associated with touching or holding them. In recognizing that live, tactile animal encounters make a significant difference in a person's perception of that animal (Shiloh et al., 2003), it is likewise important to discern and understand what makes that encounter so worthwhile and beneficial for the participant. 


\section{Theoretical and Conceptual Framework}

Live animals have been providing memorable and beneficial learning experiences for decades. Studying the use of animals in educational settings is more novel. Little is known qualitatively about how one's physical interaction with animals in an educational setting may influence learner outcomes. Sherwood et al. (1989) were some of the first to call for more research on the link between animal handling and positive affective outcomes, reporting that positive changes in student attitudes (short and long-term) were statistically greater when students handled live animals. Others have reported emotional benefits of physically touching an animal when compared to simple observation (Kidd \& Kidd, 1995), including the touching of nonvenomous snakes (Ballouard et al., 2012; Stanford, 2014). Reptiles, such as snakes, have received more attention because of stereotypes often associated with such species. Although Klingenberg (2014) suggested the impact of touching rather than observing an animal impacts emotional encouragement and positively alters cognitive outcomes, does holding an animal produce different benefits?

Significant psychological benefits can result from touching an animal (Hummel \& Randler, 2012; Mallon, 1992; Meadan \& Jegatheesan, 2010; Siegel, 2004). Giving young children a chance to interact with animals of any kind, especially those with negative preconceptions (snakes), can help to create positive formative experiences in addition to correcting existing negative behaviors. In fact, if students have an initial negative response to an animal that does not exclude them from being able to overcome that initial perception with the assistance of a new experience and possibly even develop an affinity for the animal throughout their life (Bixler et al., 1994; Shalev \& Ben-Mordehai, 1996). Shalev and Ben-Mordehai (1996) argued that when given the opportunity to form positive interactions with feared organisms such as snakes, the experience alters perceptions from negative to positive and can be perceived as satisfying. The experience can even be empowering (Shiloh et al., 2003). This is important for educators engaging participants in hands-on learning experiences because it suggests that the extra effort needed to facilitate experiential-based activities can have lasting benefits on learners. However, more research on the psychological effects of animal encounters is needed as it is still unknown whether varying degrees of contact with the animal (e.g., touch versus complete handling) may produce even deeper psychological benefits (Daly \& Suggs, 2010).

\section{Purpose}

The purpose of this qualitative study was to investigate the perceptions of fifth grade students who experienced a live, tactile animal encounter while participating in an educational reptile class. Given existing research supporting the effectiveness of touching live animals on participants' psychological and emotional outcomes, this study further explored the "why" of this impact and questioned if level of physical engagement with an animal can influence outcomes. Specifically, we compared touching versus holding an Eastern box turtle (Terrapene carolina) and corn snake (Pantherophis guttatus) on student outcomes. These species were selected because of their prevalence in environmental education animal encounters in the 
Southeastern United States and overall disposition as an educational animal ambassador. These species are also often used as classroom pets by science teachers (Rud \& Beck, 2003). The following research objectives guided data collection:

1. Describe the perceptions that students have of turtles and snakes after touching them with only two fingers.

2. Describe the perceptions that students have of turtles and snakes after handling them fully.

3. Describe any differences in the perceptions that students have of turtles and snakes based on the intensity of their touching encounter.

\section{Methods}

\section{Research Context Student Selection}

For the purpose of this study, the student participants were fifth grade elementary school students from a private Christian elementary and middle school in the Southeastern United States. Students attended the Barrier Island Environmental Education Center reptile class where prior research investigating animal touching in an educational setting had been conducted with students and adults of various ages. A convenience sample of students from the participating school was obtained, and students experiencing either a presentation involving two-finger touching of the Eastern box turtle and corn snake or full handling of the same two species were invited to participate in the study. Students had not previously attended educational activities at the center and, when possible, were unaware which group experienced touching or full handling to prevent the introduction of bias

\section{Educator Selection}

For the purpose of this study, the lead author acted as the sole educator in an effort to maintain consistency in presentation style between the two-finger touching groups and full handling groups. This individual had been teaching environmental education using reptiles for more than five years. Having the dual role of educator and researcher further employed the use of Creswell's (2012) persistent observation techniques, as the educator could directly observe and interact with the students as teaching occurred.

\section{Data Collection}

Prior to the school's visit to the education center, the researcher made a visit to the participating school in order to build trust with participants and learn the classroom culture. Each of the three fifth grade classes which came to the center were visited, and students had the chance to meet the researcher/educator and ask questions about their potential involvement in the study and visit to the education center. Once on site, students experiencing either the presentation with a two-finger touch encounter with the Eastern box turtle and corn snake or a presentation with complete handling of the Eastern box turtle and corn snake (if comfortable doing so) were invited to participate in a focus group with the educator/researcher. Students were made to feel comfortable in sharing their responses by being given a set of group discussion guidelines by the researcher. These guidelines followed 
suggestions from Gibson's (2014) recommendations for interviews with children. In addition, responses to introductory demographic type questions were asked at the beginning of the discussion to extract rich data about prior experiences with reptiles and animals in general. Questions about students' pets and reptile familiarity allowed the researcher to interpret previous levels of contact that participating students had with animals.

The researcher conducted four focus groups of three to five students each in a classroom on site with students who had submitted a parental permission form. The first focus group consisted only of students who two-finger touched the animals, while the second group consisted only of students who fully handled the animals. The third and fourth focus groups each contained a mixture of students who either two-finger touched or held an animal. The distinction between classes that received either the two-finger touch or full handling experience was based on the educator's discretion in order to distribute equally the experiences among each of the six total presentations that were given to the school. Each educational presentation consisted of 15 students from the school and lasted approximately one hour. Each of the four focus group discussions lasted 25 to 40 minutes, were audio recorded, and transcribed verbatim.

\section{Data Analysis}

Prolonged engagement and persistent observation in the field, which included a visit to the classroom of the participating school, helped develop initial trust and rapport with youth participants. Once focus group data were transcribed, member-checking was used to reflect with youth back in their school to ensure accuracy of their accounts (Lincoln \& Guba, 1985). The researcher also used methodological journals to ensure consistency in facilitating each focus group. Themes were derived from focus group responses and domain analysis, a form of content analysis, was used to further summarize the raw data into categories (Spradley, 1980). From the themes and constructs found in the focus groups, a cross tabulation was made of the perceptions of the students from the groups that either two-finger touched or fully held the turtle and snake.

Subjectivity of the researchers was considered during data collection and analysis. The lead author has worked in the field of environmental education for nearly 10 years and has experience using animals as teaching tools in formal and nonformal educational settings. The second author has worked in environmental education for 25 years and teaches courses in the use of live animals as message ambassadors.

\section{Findings}

Four recurring themes emerged from the raw data following focus groups with the fifth-grade students who touched or held the Eastern box turtle and/or corn snake. According to these students, learning with live, tactile animal encounters involved: (a) novelty, (b) confidence, (c) discovery, and (d) empathy. These overarching themes were then further broken down into sub-themes to describe participant experiences with greater richness. 
Five students from the touching groups participated and eleven students from the holding groups participated. There were eight females and eight males and most students had some prior animal interaction experience with a snake or turtle (see Table 1).

\section{Table 1}

Sample Demographics and Level of Animal Interaction (Two-finger Touch or Hold)

\begin{tabular}{|c|c|c|c|c|}
\hline Participant & Sex & Pets at Home & $\begin{array}{l}\text { Prior Animal } \\
\text { Interactions }\end{array}$ & $\begin{array}{l}\text { In-Class Animal } \\
\text { Interactions } \\
\text { (snake and turtle) }\end{array}$ \\
\hline \multicolumn{5}{|c|}{ Focus Group 1} \\
\hline P1T & M & Fish, dog & $\begin{array}{l}\text { Touched snake, } \\
\text { turtle }\end{array}$ & Touched both \\
\hline $\mathrm{P} 2 \mathrm{~T}$ & $\mathrm{~F}$ & Undetermined & Touched turtle & Touched both \\
\hline P3T & $\mathrm{F}$ & None & Touched snake & Touched both \\
\hline \multicolumn{5}{|c|}{ Focus Group 2} \\
\hline $\mathrm{P} 4 \mathrm{H}$ & M & Hedgehog & Held snake & Held both \\
\hline $\mathrm{P} 5 \mathrm{H}$ & M & 2 dogs, snakes (past) & Both & Held both \\
\hline $\mathrm{P} 6 \mathrm{H}$ & $F$ & 2 dogs, hamster & $\begin{array}{l}\text { Touched snake, } \\
\text { turtle }\end{array}$ & Held both \\
\hline $\mathrm{P} 7 \mathrm{H}$ & $\mathrm{F}$ & $\begin{array}{l}\text { Dog and hermit } \\
\text { crabs }\end{array}$ & $\begin{array}{l}\text { Held snake, touched } \\
\text { turtle }\end{array}$ & Held both \\
\hline \multicolumn{5}{|c|}{ Focus Group 3} \\
\hline P8T & $\mathrm{F}$ & $\begin{array}{l}\text { Dog, bearded } \\
\text { dragon }\end{array}$ & Touched snake & Touched both \\
\hline $\mathrm{P9H}$ & M & Dog & $\begin{array}{l}\text { Touched snake, } \\
\text { turtle }\end{array}$ & Held both \\
\hline $\mathrm{P} 10 \mathrm{H}$ & M & 2 dogs and 1 cat & $\begin{array}{l}\text { Touched snake, } \\
\text { turtle }\end{array}$ & Held both \\
\hline $\mathrm{P} 11 \mathrm{H}$ & M & Cat & $\begin{array}{l}\text { Touched snake, } \\
\text { turtle }\end{array}$ & Held both \\
\hline \multicolumn{5}{|c|}{ Focus Group 4} \\
\hline $\mathrm{P} 12 \mathrm{H}$ & M & None & Held snake & Held both \\
\hline $\mathrm{P} 13 \mathrm{H}$ & $\mathrm{F}$ & 3 dogs & Touched snake & Held both \\
\hline $\mathrm{P} 14 \mathrm{H}$ & $\mathrm{F}$ & Dog & Touched snake & Held both \\
\hline P15T & $\mathrm{F}$ & None & Touched turtle & Touched turtle only \\
\hline $\mathrm{P} 16 \mathrm{H}$ & M & Dog & $\begin{array}{l}\text { Touched snake, } \\
\text { turtle }\end{array}$ & Held both \\
\hline
\end{tabular}

Note. $\mathrm{P \#}=$ participant number, $\mathrm{T}=$ touching, $\mathrm{H}=$ holding, $\mathrm{M}=$ male, $\mathrm{F}=$ female. 


\section{Novelty}

\section{Animal Novelty}

Students from focus group 1, where they only two-finger touched the animals, in particular discussed the idea of novelty being a reason that a certain animal, either the box turtle or corn snake, was most memorable to them. According to P1T,

I liked the turtle because, snakes, usually when I go places like this, we get to touch snakes and stuff. They always bring out corn snakes and types of snakes, and just...like I usually don't see turtles and box turtles, and I really like them.

P2T also commented, "I thought about the snake because I never touched one before today, so it was kind of cool because it was different." These students felt that having an experience with an animal that they had never interacted with before, or had only limited interactions with, made a significant impact on what they remembered from the live encounter.

\section{Uniqueness of Experience}

Other students in all four focus groups expressed the idea that novelty of the experience itself, touching or holding a box turtle or corn snake, was most memorable. When asked which animal stuck out to them the most, P3T commented that,

I think the snake [stuck out the most] because it's just so neat because normally I feel you wouldn't normally be able to touch them - you just learned about them in class...I thought it was really cool because you could see all the different features of the snake and not just the picture... and I also thought it was going to feel really hard, like hard scaly, but it was a lot softer and a lot smoother.

Students in all four focus groups were asked to react to a scenario where only a video of a turtle and snake were shown without the live specimens. P3T reacted by saying,

I would be a little upset because I honestly really still would kind of be afraid of snakes; and I really just kind of thought snakes were mostly super hard, but they're really not because I got to touch the turtle and the snake. It just makes you get to know them better and, like, and learn more than if we just watched a video. I probably wouldn't pay attention to the video. It catches your attention when you're learning and you actually get to touch them.

These students reported that they were benefiting more from a live touching encounter over a video because it was an experience that they could not normally have in their typical classroom learning environment and they expected that type of experience at an educational center.

\section{Element of Fun (feeling animal movement)}

Students in focus groups two, three, and four where holding the animals was emphasized (see Table 1) felt that being able to observe and even feel an animal's behavior and reaction to being touched and held by a human helped the students see a different side of the animal and enhance their learning experience. Being in the moment was important to $\mathrm{P} 5 \mathrm{H}$ because live action was more exciting,

I think if you can't touch or hold the animal, you shouldn't show it. You should do a video, so to touch it you don't feel bad. Like an aquarium - it's different because you see there's something in action. 
This student felt that it was a disappointment to have only the chance to see, not hold, a live animal. $\mathrm{P} 12 \mathrm{H}$ also commented that, "I would be pretty sad because that's pretty fun, actually getting to hold and that's kind of the point, really." These students associated visiting an environmental education center with the expectation of getting to hold a live animal.

\section{Confidence}

\section{Reduced Fear}

Focus groups one through four also shared similar comments on the topic of increased confidence after their animal encounter. Several students expressed that they were worried or scared prior to the encounter, but felt better afterwards. After a touching encounter, P3T said, I also like the snake because I just think it's so neat to actually be able to touch it, and also normally I would think that I would be scared of snakes; but they can't really harm you unless you harm it and get too close to it. They're really not that scary.

This initial discomfort or fear would have made it harder to learn about the animals, as reported by the students. Increased confidence made it easier to connect with the animals.

After a holding encounter, $\mathrm{P} 7 \mathrm{H}$ responded, "When I first touched the snake, I was a little scared that it might bite me; but then I got comfortable with it. And now I'm just, like, it just felt much better and was cooler." This student further stated that, "For snakes, if it bites you, you shouldn't just not try touching it again because then it's just like riding your bike - when you fall off and you don't try again."

\section{Increased Comfort}

When asked about how they would feel if they encountered a box turtle or corn snake (safe/healthy or one that needed aid) in the wild after meeting one in captivity, P3T commented,

If I saw a snake in the wild I would probably just try to stay calm and slowly walk away. I don't want to be near that, but after today I think I would be a little more comfortable but still try to keep my distance from it. And for turtles...kind of the same answer as them - like if one was stuck in the middle of the road or if you could tell it couldn't turn over like before, I would definitely help it or find someone to help it.

In focus group two, P4H added, 'Yeah. Before you took it [snake] out, I was like, 'This is fine.' But once you took it [snake] out I got a little bit more nervous, but once I actually started touching it, I got used to it." Interacting with the snake and seeing the instructor interact with the snake helped this student to become more comfortable with an animal that was previously unnerving.

In focus group three, students also commented that they were slightly afraid of the turtle because it could bite or scratch, but when they had the chance to interact with it, they were able to see it in a different way that helped to increase their comfort levels. Seeing the turtle move and reacting to interactions made the students laugh, which increased their comfort. $\mathrm{P9H}$ commented, "I don't really know how to say it about the turtle, but I know how to say it more about the snake. If it seems scary to you, make those scary things in your head look funnier and then you'll like it." 


\section{Discovery}

Another pervasive theme among all four focus groups was that of personal discovery. Students in both the touching and holding groups reported that part of the uniqueness of the experience, increased comfort, and having more fun was because they were experiencing something themselves, firsthand. Experiential encounters made a difference to these students in terms of what they were learning, getting to know the animal better, and relating to the animal. As $\mathrm{P} 4 \mathrm{H}$ who held the corn snake recounted,

Well, I really learned more about it [snake] because, like, you get to feel it and discover things by yourself...you don't tell them something, like if you don't tell us that it's scaly and you feel it, you can see [feel] it's scaly.

$\mathrm{P} 5 \mathrm{H}$ who also held the corn snake added, "It's like just discovering something on your own first - it's something different. And so at this age we think it's, like, cooler if we have something done differently than other people."

Feeling the different animals really made an impact over just seeing the animals themselves. Although observing was still beneficial, the students would not have made personal discoveries without the chance to explore with the additional sense of touch. Rather than taking someone's word for it, discovering something themselves helped students in this study build more connections. The experience of holding the animals made the animal more real to some students, as P4H said, "I just feel like it's more real...you learn more."

\section{Empathy}

\section{Desire to Help}

Overwhelmingly, multiple students in all four focus groups reported feelings of empathy in relation to the corn snake and Eastern box turtle. While not all students felt the same about both animals, empathetic tendencies were reported for both from different students. Touching an animal helped to create feelings of friendship for P3T in focus group one, "maybe you could actually kind of meet them. It's almost like you are friends with them sort of." Both focus group one and two where students touched (focus group 1) and held (focus group 2) the turtle and snake had students comment on putting themselves in the place of one of the animals in response to their habitat being lost or the animal being killed as a result of human activity. As P3T shared,

Before this class I probably would have been like, oh well, you know there are bunch of other corn snakes, but after, now that I realize how neat they are, I would be a little upset, you know. You didn't have to do that [kill a snake]. You could have just let it be, you know. They probably would have moved somewhere else eventually.

$\mathrm{P} 13 \mathrm{H}$ also responded, "So I would feel bad for the snake and the human because the snake was dead; but I think that for my friend and neighbor, because they didn't know..." This student commiserated not only the death of the animal mentioned in a scenario, but also the human choice because that person might have made a different decision had they known better, and they might be disappointed in themselves once they realized what they had done.

Students also reported actions they would take to help these animals, such as advocating for them, educating others about them, or calling someone to help them if they could not or did 
not feel comfortable to help the animal themselves. As P7H stated, "I would say, "What if you were the snake and someone killed you because you were living in your habitat?"' and P9H added, "Kind of the same thing as $\mathrm{P} 11 \mathrm{H}$ and $\mathrm{P} 10 \mathrm{H}$ - God put all the animals here for a reason; and if you're one of those animals, you would want help too." Being able to put themselves in the place of the animals showed that touching or holding helped students to connect more to the corn snake and Eastern box turtle. As P8T shared, "I think that if you would get your own house taken away, then you would want someone to help you. You would want to do the same thing back to other people, but we could do it for animals too."

\section{Respect}

Some students also reported that there was an appropriate time, setting, and place for touching animals such as turtles and snakes. When shown photographs that disallowed petting or touching of animals, most students agreed with the signs. Students would understand not handling or touching wild animals that are not accustomed to human contact. As $\mathrm{P} 6 \mathrm{H}$ and $\mathrm{P} 7 \mathrm{H}$ responded, "You shouldn't just go touching and pushing and shoving because what if someone did that to you always and tried to pick you up and touch you all the time? It's just uncomfortable."

P1T also commented on the no touching signs with, "Yeah. I can understand why. I can understand because the turtle's just doing its own thing. He doesn't need someone to just come up and be like "ooh!" and start messing with him." P2T added, "...like P1T said, that turtle isn't really used to being touched, and also I think some animals just don't really probably like being touched as much." Even though these students only interacted with a two-finger touch, there were empathetic attitudes demonstrated for the snake and turtle in relation to how the animals themselves would feel about interacting with humans. Feelings of empathy toward animals have been found to influence positive environmental behaviors (Batson, 1991; Fuhrman, 2007).

\section{Conclusions, Discussion, and Recommendations}

Across all four focus groups, students discussed their reactions to touching and holding the corn snake more often than the Eastern box turtle. The turtle may have been brought up less than the snake because, as Shalev and Ben-Mordehai (1996) postulated, snakes produce more excitement, intrigue, fear, and other emotions compared to other animals. Fuhrman and Rubenstein (2017) reported that the novelty of handling a snake and excitement that such interaction can have on observers may be one reason why educators select snakes to use in teaching demonstrations. This suggests that agriscience teachers may consider live or model teaching tools which have a unique behavior or feature to use as an interest approach as they create an environment conducive for learning. However, novelty was especially prevalent where students only touched either the snake or turtle. Out of the five students who two-finger touched either the turtle or snake, all reported positive feelings about the animals with which they interacted. However, these students also felt that it was not always appropriate to touch animals, even though it was a beneficial learning experience. All educators should emphasize 
the importance of a sense of caution when engaging with any animal. When unpredictable behaviors in animals occur, educators should highlight these "teachable moments" and use them during reflections with students.

All five of the two-finger touch students also had prior experience touching reptiles (see Table 1), and some even shared prior experiences helping or encountering similar animals in the wild or in their own yard. Each student touched something in the classroom that they had touched previously, even if only minimally. These students still reported that novelty was what made the corn snake stand out over the Eastern box turtle. Touching also seemed to help students get to know the animals better, aligning with previous findings (Ballouard et al., 2012; Bixler et al., 1994; Shalev \& Ben-Mordehai, 1996; Stanford, 2014).

Students who experienced holding the corn snake and Eastern box turtle emphasized the uniqueness of the experience and feeling it move in their hands. While virtually all of the students in this group had previous experience touching snakes and turtles, few of them reported a significant holding experience. Many of these students also had pet dogs or cats at home, which could have influenced their animal interaction confidence. As seen with the touch group, many of these students also had other prior experiences that may have contributed to their feelings about these animals. Some of these students had encountered turtles or snakes in the wild, and had even taken some action to help or move some turtles or snakes away from danger or roadways. Whether the animal ambassador is a turtle, snake, or other agriculturallyrelated animal, educators should consider relying on students with previous animal encounter experiences to help those students with less experience as a mentor. These students also displayed a high amount of empathy towards the animals, reporting feelings of sadness at the idea of box turtles or corn snakes being killed by human activity. Compared to those who touched the corn snake or Eastern box turtle, several students who held the snake or turtle mentioned how the experience helped them "learn more," something for additional exploration compared to only touching (Fuhrman \& Ladewig, 2008).

Overall, regardless of whether students touched the corn snake or Eastern box turtle or fully held the animal, participants noted the uniqueness of the experience and their empathy for the animal and its habitat. Through their touching and holding experiences, the students felt like they learned things about the animal that they otherwise would not have been able to know. Students felt more engaged, had more fun, and paid more attention when they had a direct, experiential opportunity to interact with a snake or turtle. This is important for agricultural and environmental educators with opportunities for students to either touch or hold an animal. This study found that both touching and holding experiences were beneficial in their own ways and should be encouraged, when appropriate.

Given our findings, we recommend that educators seek out ways to create opportunities for students that allow for individual, direct, and novel experiences during an animal encounter. Such an encounter would allow students to engage with animals in a manner that produces higher quality learning, a deeper sense of empathy for the animal, and helps with overcoming fears or misconceptions of these animals. This study found that when safety and liability issues 
prevent learners from completely holding a snake or turtle, educators should consider the equally positive outcomes that can result from touching a snake or turtle with two fingers and provide opportunities for such experiences.

\section{References}

Balis, L. E., Marshall, C., Malcolm, A., \& Harden, S. M. (2019). Goat yoga: Preliminary implications for health, agriculture, and 4-H. Journal of Extension, 57(3). https://archives.joe.org/joe/2019june/pdf/JOE_v57_3iw4.pdf

Ballouard, J-M., Brischoux, F., \& Bonnet, X. (2011). Children prioritize virtual exotic biodiversity over local biodiversity. PLOS ONE, 6(8), Article e23152. https://doi.org/10.1371/journal.pone.0023152

Ballouard, J., Provost, G., Barre, D., \& Bonnet, X. (2012). Influence of a field trip on the attitude of school children toward unpopular organisms: An experience with snakes. Journal of Herpetology, 46(3), 423-428. https://doi.org/10.1670/11-118

Batson, C. D. (1991). The altruism question: Toward a social-psychological answer. Lawrence Erlbaum Associates, Inc.

Bixler, R. D., Carlisle, C. L., Hammitt, W. E., \& Floyd, M. F. (1994). Observed fears and discomforts among urban students on field trips to wildland areas. The Journal of Environmental Education, 26(1), 24-33. https://doi/org/10.10180/00958964.1994.9941430

Creswell, J. W. (2012). Standards of validation and evaluation. In L. Habib, B. Bauhaus, \& M. Masson (Eds.), Qualitative inquiry and research design: Choosing among five approaches (pp. 243-268). Sage Publications, Inc.

Daly, B., \& Suggs, S. (2010). Teachers' experiences with humane education and animals in the elementary classroom: Implications for empathy development. Journal of Moral Education, 39(1), 101-112. https://doi.org/10.1080/03057240903528733

Fuhrman, N. E. (2007). Predicting commitment to engage in environmentally responsible behaviors using injured and non-injured animals as teaching tools [Doctoral dissertation, University of Florida]. https://ufdcimages.uflib.ufl.edu/UF/E0/02/12/89/00001/fuhrman n.pdf

Fuhrman, N., \& Ladewig, H. (2008). Characteristics of animals used in zoo interpretation: A synthesis of research. Journal of Interpretation Research, 13(2), 31-42. https://doi.org/10.1177/109258720801300203 
Fuhrman, N. E., \& Rubenstein, E. D. (2017). Teaching with animals: The role of animal ambassadors in improving presenter communication skills. Journal of Agricultural Education, 58(1), 223-235. https://doi.org/10.5032/jae.2017.01223

Gibson, J. E. (2014). Interviews and focus groups with children: Methods that match children's developing competencies. Journal of Family Theory \& Review, 4(2), 148-159. https://doi/10.1111/j.1756-2589.2012.00119.x

Hudson, S. J. (2001). Challenges for environmental education: Issues and ideas for the 21st century. BioScience, 51(4), 283-288. https://doi.org/10.1641/00063568(2001)051[0283:CFEEIA]2.0.CO;2

Hummel, E., \& Randler, C. (2012). Living animals in the classroom: A meta-analysis on learning outcome and a treatment-control study focusing on knowledge and motivation. Journal of Science Education and Technology, 21, 95-105. https://doi.org/10.1007/s10956-0119285-4

Kidd, A. H., \& Kidd, R. M. (1995). Developmental factors in positive attitudes toward zoo animals. Psychological Reports, 76(1), 71-81. https://doi.org/10.2466/pr0.1995.76.1.71

Klingenberg, K. (2014). 'Primärerfahrung' with living animals in contrast to educational videos: A comparative intervention study. Journal of Biological Education, 48(2), 105-112. https://doi.org/10.1080/00219266.2013.849285

Kreger, M., \& Mench, J. (1995). Visitor-animal interactions at the zoo. Anthrozoos, 8(3), 143158. https://doi.org/10.2752/089279395787156301

Lincoln, Y., \& Guba, E. G. (1985). Naturalist Inquiry. Sage Publications.

Louv, R. (2006). Last child in the woods: Saving our children from nature-deficit disorder. Algonquin Books.

Mallon, G. (1992). Utilization of animals as therapeutic adjuncts with children and youth: A review of the literature. Child and Youth Care Forum, 21(1), 53-67. https://doi.org/10.1007/BF00757348

Meadan, H., \& Jegatheesan, B. (2010). Classroom pets and young children: Supporting early development. Young Children, 65(3) 70-77. https://www.proquest.com/docview/873822959?pqorigsite=gscholar \&fromopenview=true

Newberry, M. G., Fuhrman, N. E., \& Morgan, A. C. (2017). Naming "animal ambassadors" in an educational presentation: Effects on learner knowledge retention. Applied 
Environmental Education \& Communication, 16(4), 223-233.

https://doi.org/10.1080/1533015X.2017.1333051

Pedersen, H. (2010). Animals in schools: Processes and strategies in human-animal education. Purdue University Press.

Rud, A. G., \& Beck, A. M. (2003). Companion animals in Indiana elementary schools. Anthrozoos, 16(3), 241-251. https://doi.org/10.2752/089279303786992134

Shalev, A., \& Ben-Mordehai, D. (1996). Snakes: Interactions with children with disabilities and the elderly - some psychological considerations. Anthrozoos, 9(4), 182. https://doi.org/10.2752/089279396787001446

Sherwood, K. P, Rallis, S. F., \& Stone, J. (1989). Effects of live animals vs. preserved specimens on student learning. Zoo Biology, 8(1), 99-104. https://doi.org/10.1002/zoo.1430080112

Shiloh, S., Sorek, G., \& Terkel, J. (2003). Reduction of state-anxiety by petting animals in a controlled laboratory experiment. Anxiety, Stress \& Coping, 16(4), 387-395. https://doi.org/10.1080/1061580031000091582

Siegel, W. (2004). The role of animals in education. ReVision, 27(2), 17-26. https://go.gale.com/ps/i.do?id=GALE\%7CA127936654\&sid=googleScholar\&v=2.1\&it=r\&l inkaccess=abs\&issn=02756935\&p=AONE\&sw=w\&userGroupName=highlands_edu

Spradley, J. (1980). Participant observation. Holt, Rinehart, \& Winston.

Stanford, A. (2014). Can I touch it?: Zoo program impacts. IZE Journal, 50, 64-67. https://www.ipcn.nsw.gov.au/resources/pac/media/files/pac/projects/2016/11/thesydney-zoo/supplementary-assessment-and-information/annexure-11--academicresearch-on-animal-interaction.pdf

Strife, S., \& Downey, L. (2009). Childhood development and access to nature: A new direction for environmental inequality research. Organization and Environment, 22(1), 99122. https://doi.org/10.1177/1086026609333340

Trainin, G., Wilson, K., Wickless, M., \& Brooks, D. (2005). Extraordinary animals and expository writing: Zoo in the classroom. Journal of Science Education and Technology, 14(3), 299304. https://doi.org/10.1007/s10956-005-7195-z

United Nations Department of Economic and Social Affairs. (n.d.). Sustainable development goals. https://sdgs.un.org/goals/goal4 
Von Bergen, C. W. (2015). Emotional support animals, service animals, and pets on campus. Administrative Issues Journal: Connecting Education, Practice, and Research, 5(1), 1534. https://doi.org/10.5929/2015.5.1.3

(C) 2021 by authors. This article is an open access article distributed under the terms and conditions of the Creative Commons Attribution license (http://creativecommons.org/licenses/by/4.0/). 